\title{
Certified sick leave as a non-specific morbidity indicator: a case-referent study among nurses
}

\author{
Renée Bourbonnais, Alain Vinet, Michel Vézina, Suzanne Gingras
}

\begin{abstract}
A case-referent study assessed the association between medically certified sick leave from work and some occupational characteristicsnamely, two work load indices (nurse patient ratio and patients' average duration of stay) and hospital and care unit. Study participants were nurses from seven general hospitals in Québec City who had been employed for at least six months at the time of study. Cases $(n=184)$ experienced at least one episode of medically certified sick leave for a diagnosis "most likely to be related to work load" between 1 January 1984 and 31 May 1987 . Referents $(n=1165)$ were chosen from subjects who had no such leave, whatever the medical reason, and were matched to cases by the incidence density sampling method. Occupational data were collected from employment records and administrative files. Analysis was by multiple logistic regression. Significant associations were found between sick leave and nursepatient ratio among head nurses, patient's duration of stay, and one hospital. Sick leave was more frequent among full time permanent nurses and among those on night and evening schedules. These associations were independent of age, duration of service in this hospital or in the actual job assignment, and care unit. This study supports the relevance of using sick leave as a non-specific indicator of health outcomes.
\end{abstract}

Data from 1985 showed that in Canada, annual time lost for absence from work was about 12.7 days per employee. Real cost was about 1000 dollars per employee, more than 10 billion dollars annually for Canada. ${ }^{1}$ This situation is not a prerogative of this country and the interest of companies and governments in reducing this phenomenon is understand-

Laval University, Québec, Province of Québec, Canada

$\mathbf{R}$ Bourbonnais, A Vinet, $M$ Vézina, $S$ Gingras able, as are the abundant studies on the subject by management specialists. ${ }^{2}$

Compared with Ontario and the whole of Canada for the year 1986-7 the province of Québec had the highest annual incidence of leave for illness or for personal reasons for all occupations. ${ }^{1}$ These incidence rates were 5.82 for Québec, 5.71 for Ontario, and 5.21 for Canada. For health professionals, the rate were higher; 9.4 for Québec, 6.8 for Ontario, and $7 \cdot 3$ for the whole country.

These figures indicate the need to study the phenomenon of sick leaves and to try to identify their cause and confirm that a study of one of the largest groups of health professionals-namely, nurses working in hospital settings-would be particularly relevant. For some years in Québec, nurses have demanded better working conditions and some of the actual conditions may affect nurses' health.

Through a review, published in precedent papers ${ }^{34}$ we identified some of the main occupational and non-occupational factors related to sick leave among nurses. Non-professional factors include age, sex, seniority or duration of service, marital state and parental responsibilities, previous absence record, and personality. Professional factors include the size and type of organisation, the type of work or hospital department, the type of patient and care, the nursepatient ratio, the patient's duration of stay in the hospital, the title or function, full time or part time job, permanent or temporary work, and work schedules.

This paper focuses on the association between nurses' certified sick leave for a diagnosis "most likely to be related to work load" and certain characteristics of their work organisation. Our hypothesis was that among nurses, the heavier the work load, the more sick leave nurses would take.

\section{Population and methods}

We conducted a case-referent study of paid certified sick leaves that occurred from 1 January 1984, to 31 May 1987 in seven general hospitals in the Québec city region. For these hospitals, we had access to a unique data bank from a common collective insurance company; this guaranteed a certain uniformity in the administrative control of sick leave. The 
seven hospitals were also bound by the same collective bargaining, all the nurses being members of the same union. Everyone who had received indemnity at least once during the study period was recruited as a potential case. Referents were chosen at random from the same hospitals according to the incidence density sampling method, which pairs a case with a referent chosen among the nurses who had no such leave at the respective time. Cases and referents had to have occupied a position for at least six months before the date that they were included in the study and had to have remained in the same hospital during the study period. Men were excluded because of insufficient numbers.

\section{DEFINITION OF VARIABLES}

The dependent variable was defined using the admissibility criteria for compensation-namely, leaves that were registered from the sixth day of sick leave for full time permanent nurses and from the eighth day of sick leave for the others.

Analyses were firstly done on all sick leaves whatever the reason or diagnosis on the medical certificate $(n=1165),{ }^{3}$ because we considered that certain work characteristics would have a non-specific effect on health. ${ }^{2}$ Our model assumes that an overload is associated with all cause morbidity through a premature wear process.

Several health problems leading to sick leave are not work related, however, and their inclusion in the measure of effect would eventually hide a real association between certain work exposures and sick leave for other health problems. Consequently, we restricted the health problems to those for which there was evidence from other studies of an association with work organisation and especially with the nurse's work load. Therefore, the results presented in this paper concern only the cases who took a sick leave for a medical reason "most likely to be related to the work load" as determined by three occupational physicians familiar with work organisation risk factors.

The data from the insurance company included information on health problems as recorded on the mandatory medical certificate for compensated sick leaves. (They did not include leave for work accidents or health problems legally acknowledged to have occurred through the work process, as they were compensated by a paragovernmental insurance organism.) Three occupational physicians classified the 580 health problems of the insurance company's classification into three categories: group A contained the diagnoses "most likely to be related to physical or mental work load"; group B contained the diagnoses "possibly related to work load"; and group C contained the diagnoses "not related to work-load.".

This classification was done independently by the three physicians who were also blind as to whether the diagnosis concerned a case or not. Complete agreement between the physicians was reached after three iterations, each one having obtained respectively $73.8 \%, 92 \cdot 1 \%$, and $100 \%$ of concordant diagnoses.

Among all the diagnoses, only 10 were classified in the group "most likely to be related to work load" but they represented $15.8 \%$ of the reasons for certified sick leave and concerned 184 of the 1165 nurses in the study.

These diagnoses were mostly mental or psychosomatic problems and were found in the category of mental disorders of the International Classification of Diseases $(\mathrm{ICD}-9)^{5}$ as nervous breakdown $(300 \cdot 4 ; \mathrm{n}=$ 135), neurocirculatory asthenia (306.2; $n=14$ ), migraine (346.9; $\mathrm{n}=11$ ), exertion (994.5; $\mathrm{n}=10$ ) and others (anxiety or anguish (300.0), mental exhaustion (300.5), neurosis (300.9), tachycardia (427.2), insomnia (780.5), physical exhaustion $(780 \cdot 7) ; \mathrm{n}=14)$.

In this paper, cases were nurses who had been compensated for a sick leave "most likely to be related to work load" $(n=184)$ and referents $(n=$ 1165) were all the nurses who did not have any compensated sick leave at the time a potential case turned up.

No significant differences occurred for the date at which the sick leave occurred between the three diagnostic groups. Sick leaves for group A, group B, or group $C$ happened in a regular manner throughout the study period. Hence referents chosen on the basis of the date of occurrence of sick leave for each case were not different if they were matched to a case from group A, B, or C and all the referents could be part of the analysis.

Four exposure variables were related to the nurse's work load. The nurse-patient ratio is the number of paid nursing hours divided by the number of patient hours. It directly quantifies the work load; the lower the ratio, the greater the work load. The patients' average duration of stay in the hospital is an inverse measure of the nurse's work load as the need for nursing care is always greater in the first few days of a stay in hospital; the shorter the duration of stay, the greater the work load. Because the work load varies according to the type of patients and the care provided, the nurse-patient ratio and the average duration of stay in the hospital were adjusted according to the care unit to which each nurse was assigned. Thus the original values of these variables were replaced in the analysis by a low, medium, and high level, established according to the tertiles of the distribution of the study's subjects within each care unit. Also, for both exposure variables we used the mean value of the six months preceding the date of inclusion in the study for each nurse.

The care unit was used as a variable characterising the weight of the work load in relation to the type of 
patients and therefore as an indirect measure of the nurse's work load. In fact, the work load can vary considerably according to the seriousness of the illness, the prognosis, and the patient's functional autonomy. The care units were grouped into seven homogeneous categories in terms of nursing care and type of patients. The care unit termed varied is used as a reference value because there is no particular exposure risk in this group of units. The hospital was retained as an exposure variable as the management of sick leave (authorisation, compensation, sick leave replacement) may vary from one establishment to another and thus influence the amount of sick leave. The hospital with the greatest number of insured nurses was used as the reference hospital.

The covariables in the analyses were: age, seniority in the hospital and seniority within the last position held, job classification (full time permanent nurses in one category, part time and occasional nurses in another), work schedule (day, evening, night, and shift), and job title (assistant head nurses or team leaders and all other nurses).

\section{DATA COLLECTION}

Because of the collective agreement, interviews with union representatives and employers enabled us to verify that the management policy for sick leave was

Table 1 Distribution of cases and referents according to various covariables

\begin{tabular}{|c|c|c|c|c|c|}
\hline Covariables & $\begin{array}{l}\text { Cases } \\
\text { No }\end{array}$ & $(\%)$ & $\begin{array}{l}\text { Refer } \\
\text { No }\end{array}$ & $\begin{array}{l}\text { rents } \\
(\%)\end{array}$ & $\begin{array}{l}p \text { Value } \\
\left(\chi^{2}\right)\end{array}$ \\
\hline $\begin{array}{r}\text { Age (y): } \\
20-29 \\
30-39 \\
40-49 \\
\geqslant 50\end{array}$ & $\begin{array}{l}42 \\
94 \\
32 \\
16\end{array}$ & $\begin{array}{r}(22 \cdot 8) \\
(51 \cdot 1) \\
(17 \cdot 4) \\
(8 \cdot 7)\end{array}$ & $\begin{array}{r}273 \\
604 \\
204 \\
84\end{array}$ & $\begin{array}{r}(23 \cdot 4) \\
(51 \cdot 9) \\
(17 \cdot 5) \\
(7 \cdot 2)\end{array}$ & 0.925 \\
\hline $\begin{array}{l}\text { Seniority in hospital }(y) \text { : } \\
<5 \\
5-9 \\
10-14 \\
\geqslant 15\end{array}$ & $\begin{array}{l}12 \\
68 \\
63 \\
41\end{array}$ & $\begin{array}{l}(6 \cdot 5) \\
(37 \cdot 0) \\
(34 \cdot 2) \\
(22 \cdot 3)\end{array}$ & $\begin{array}{l}135 \\
411 \\
428 \\
191\end{array}$ & $\begin{array}{l}(11 \cdot 6) \\
(35 \cdot 3) \\
(36 \cdot 7) \\
(16 \cdot 4)\end{array}$ & 0.062 \\
\hline $\begin{array}{l}\text { Seniority in last position } \\
<6 \\
6-11 \\
12-23 \\
\geqslant 24\end{array}$ & $\begin{array}{c}\text { months } \\
24 \\
24 \\
28 \\
108\end{array}$ & $\begin{array}{l}\text { s); } \\
(13 \cdot 0) \\
(13 \cdot 0) \\
(15 \cdot 2) \\
(58 \cdot 7)\end{array}$ & $\begin{array}{l}161 \\
122 \\
180 \\
702\end{array}$ & $\begin{array}{l}(13 \cdot 8) \\
(10 \cdot 5) \\
(15 \cdot 5) \\
(60 \cdot 3)\end{array}$ & 0.774 \\
\hline $\begin{array}{l}\text { Work classification: } \\
\text { Permanent full time } \\
\text { Other }\end{array}$ & $\begin{array}{r}117 \\
67\end{array}$ & $\begin{array}{l}(63 \cdot 6) \\
(36 \cdot 4)\end{array}$ & $\begin{array}{l}509 \\
654\end{array}$ & $\begin{array}{l}(43 \cdot 8) \\
(56 \cdot 2)\end{array}$ & $0.0001 \ldots$ \\
\hline $\begin{array}{l}\text { Function: } \\
\text { Head nurse } \\
\text { Nurse }\end{array}$ & $\begin{array}{r}32 \\
151\end{array}$ & $\begin{array}{l}(17.5) \\
(82.5)\end{array}$ & $\begin{array}{r}138 \\
1014\end{array}$ & $\begin{array}{l}(12 \cdot 0) \\
(88 \cdot 0)\end{array}$ & 0.038 \\
\hline $\begin{array}{l}\text { Schedule: } \\
\text { Day } \\
\text { Evening } \\
\text { Night } \\
\text { Shift } \\
\text { Unknown }\end{array}$ & $\begin{array}{l}40 \\
42 \\
32 \\
46 \\
24\end{array}$ & $\begin{array}{l}(21 \cdot 7) \\
(22 \cdot 8) \\
(17 \cdot 4) \\
(25 \cdot 0) \\
(13 \cdot 0)\end{array}$ & $\begin{array}{l}341 \\
240 \\
154 \\
268 \\
162\end{array}$ & $\begin{array}{l}(29 \cdot 3) \\
(20 \cdot 6) \\
(13 \cdot 2) \\
(23 \cdot 0) \\
(13.9)\end{array}$ & 0.396 \\
\hline
\end{tabular}

Mean age (SD) cases 36.6 (8.2) y; controls 35.8 (7.8) y $(\mathrm{p}=0 \cdot 242)$. Mean seniority in hospital (SD) cases $10 \cdot 9$. (5:0) y; $;$ controls $10.3(5.0)$ y $(p=0.097)$. Mean seniority in last position (SD) cases $45.3(42.1)$ months; controls 43.6 (42.5) months $(\mathrm{p}=0.601)$. comparable between hospitals. Occupational data for cases and referents were collected directly from the hospital files in such a way that the reviewers were unable to distinguish cases from referents. Measurement of nurse-patient ratios and duration of stay in the hospital was also done from standard hospital administrative data.

\section{ANALYSIS}

$\chi^{2}$ tests were used to compare proportions and $t$ tests to compare means. ${ }^{6}$ The measure of association was the odds ratio (OR) with its $95 \%$ confidence interval $(95 \% \mathrm{CI}){ }^{7}$ Logistic regression analysis was carried out to adjust for several variables simultaneously. ${ }^{89}$ All statistical analyses used the SAS procedure. ${ }^{10}$

\section{Results}

In the univariate analysis no significant differences were found between cases and referents for age, seniority in the hospital, or seniority in the last position held (table 1). Full time permanent nurses were absent more often than the others $(p<0.0001)$ and the head nurses were absent more often than the nurses $(p=0.038)$. No significant relation existed between work schedule and sick leave $(p=0.396)$.

As the association between the nurse-patient ratio and sick leave was not homogeneous between nurses and head nurses, interaction terms were introduced into the analysis. Table 2 shows the crude and adjusted ORs between sick leave and nurse-patient ratio among each group of nurses. For the head nurses, the association was consistent with the hypothesis: when the ratio was low and thus when the work load increased, the sick leaves increased $(\mathrm{OR}=8.23$ for low ratio and 6.62 for medium ratio among head nurses). The sick leave pattern of the other nurses showed no trend in the association but the medium and low nurse-patient ratios were related to absence (OR $=3.74$ for low ratio and 4.61 for medium ratio among nurses).

The short average duration of stay of patients in the hospital was related to sick leave: the adjusted OR $(1 \cdot 85)$ supports the study's hypothesis; the shorter the average duration of stay, the greater the work load and the greater the sick leave.

Table 2 also shows that work classification was significantly associated with sick leave. The OR was, in fact, higher among nurses with a full time permanent job than among part time nurses and occasional nurses. For work schedules, night shift $(O R=1.96)$ and evening shift $(O R=1.67)$ were associated with sick leave after controlling for the other covariables.

Table 3 shows that the association between sick leave and work in the psychiatry unit was significant on crude analysis. Although not statistically significant, the adjusted OR for the psychiatry unit was greater than the OR for any other care unit. None of 
the other care units were related to sick leave either in the crude analysis or after controlling for significant cofactors.

Only hospital 5 was significantly related to sick leave, generating less absence than the other hospitals $(O R=0.49)$. Adjusted $O R s$ were not sensibly different from the crude ORs indicating an independent effect of that hospital in the prediction of sick leave.

Table 2 Adjustment by logistic regression of the association between sick leave and work characteristics

\begin{tabular}{|c|c|c|}
\hline Exposure & $\begin{array}{l}\text { Crude OR } \\
(95 \% C I)\end{array}$ & $\begin{array}{l}\text { Adjusted } O R^{\star} \\
(95 \% C I)\end{array}$ \\
\hline $\begin{array}{l}\text { Duration of stay: } \\
\text { Long } \\
\text { Medium } \\
\text { Short }\end{array}$ & $\begin{array}{l}1.00 \\
1.07(0.72-1.57) \\
1.30(0.89-1.90)\end{array}$ & $\begin{array}{l}1.00 \\
0.99(0.56-1.73) \\
1.85(1.03-3.31)\end{array}$ \\
\hline \multicolumn{3}{|l|}{$\begin{array}{l}\text { Nurse-patient ratio: } \\
\text { Among head nurses }\end{array}$} \\
\hline $\begin{array}{l}\text { High } \\
\text { Medium } \\
\text { Low }\end{array}$ & $\begin{array}{l}1 \cdot 00 \\
5 \cdot 56(1 \cdot 48-30 \cdot 86) \\
7 \cdot 65(1.64-47 \cdot 08)\end{array}$ & $\begin{array}{l}1 \cdot 00 \\
6 \cdot 62(1 \cdot 79-24 \cdot 43) \\
8 \cdot 23(1 \cdot 97-34 \cdot 37)\end{array}$ \\
\hline $\begin{array}{l}\text { Among nurses } \\
\text { High } \\
\text { Medium } \\
\text { Low ratio }\end{array}$ & $\begin{array}{l}1.00 \\
1.43(0.85-2 \cdot 39) \\
1.16(0.72-1.92)\end{array}$ & $\begin{array}{l}1 \cdot 00 \\
4 \cdot 61(1 \cdot 33-16 \cdot 00) \\
3 \cdot 74(1 \cdot 10-12 \cdot 68)\end{array}$ \\
\hline \multicolumn{3}{|l|}{$\begin{array}{l}\text { Covariables: } \\
\text { Work classification }\end{array}$} \\
\hline $\begin{array}{l}\text { Permanent full time } \\
\text { Other } \\
\text { Schedule }\end{array}$ & $\begin{array}{l}2 \cdot 24(1.64-3.08) \\
1.00\end{array}$ & $\begin{array}{l}2.34(1.65-3.32) \\
1.00\end{array}$ \\
\hline $\begin{array}{l}\text { Day } \\
\text { Evening } \\
\text { Night } \\
\text { Shift }\end{array}$ & $\begin{array}{l}1.00 \\
1.49(0.94-2.37) \\
1.77(1.08-2.92) \\
1.46(0.93-2.30)\end{array}$ & $\begin{array}{l}1.00 \\
1.67(1.02-2 \cdot 75) \\
1.96(1.14-3.36) \\
1.43(0.88-2.31)\end{array}$ \\
\hline
\end{tabular}

*The adjusted model includes duration of stay, nurse-patient ratio, job title, interaction terms between ratio and title, job classification, and work schedule.

Table 3 Adjustment by logistic regression of the association between sick leave and work characteristics

\begin{tabular}{lll}
\hline Exposure & $\begin{array}{l}\text { Crude } O R \\
(95 \% C I)\end{array}$ & $\begin{array}{l}\text { Adjusted } O R^{\star} \\
(95 \% \mathrm{CI})\end{array}$ \\
\hline Care unit: & & \\
$\quad$ Varied & 1.00 & 1.00 \\
Short term care & $1.50(0.74-3.07)$ & $1.15(0.54-2.44)$ \\
Psychiatry & $2.77(1.14-6.76)$ & $2.05(0.78-5.37)$ \\
Long term care & $1.68(0.58-4.82)$ & $1.12(0.37-3.36)$ \\
Nursery & $1.48(0.52-4.25)$ & $1.32(0.45-3.94)$ \\
Surgical block & $1.58(0.68-3.68)$ & $1.18(0.48-2.88)$ \\
Ambulatory services & $1.02(0.43-2.39)$ & $0.76(0.31-1.87)$ \\
Preventive medicine & $1.06(0.39-2.89)$ & $0.76(0.25-2.33)$ \\
Hospital: & & \\
Hospital 2 & 1.00 & 1.00 \\
Hospital 1 & $0.61(0.36-1.05)$ & $0.71(0.40-1.25)$ \\
Hospital 3 & $0.86(0.51-1.43)$ & $0.91(0.52-1.57)$ \\
Hospital 4 & $0.61(0.36-1.03)$ & $0.68(0.38-1.22)$ \\
Hospital 5 & $0.49(0.26-0.94)$ & $0.46(0.23-0.91)$ \\
Hospital 6 & $0.70(0.41-1.18)$ & $0.64(0.37-1.12)$ \\
Hospital 7 & $0.89(0.51-1.53)$ & $0.94(0.53-1.66)$ \\
\hline
\end{tabular}

*The adjusted model includes hospital, care unit, job classification, and work schedule.

\section{Discussion}

The findings indicate that certified sick leave with compensation was not randomly distributed among the nursing population and that the work constraints in nursing at least partly explained the variations found. The nurse-patient ratio, the patient's average duration of stay in the care unit, the affiliation to a hospital and work in the psychiatry unit, the full time permanent job classification, and the night and evening work schedules influenced the occurrence of sick leaves "most likely to be related to work load". Age, duration of service in the hospital or in the actual job assignment, and care unit, apart from psychiatry, had no effect.

The association between the nurse-patient ratio and absence was consistent with the hypothesis of the lower the ratio the greater the association with sick leave. Among the head nurses, given their complex dual work load (administrative and clinical duties), which gets heavier when there is a staff shortage, this work load is especially great when the nurse-patient ratio is low. For the other nurses, a possible explanation of the weaker association could be the replacement policy for sick leave, which seems to be different when the nurse-patient ratio is high than when it is low. The presence of a high nurse-patient ratio may reflect a systematic replacement practice that would prevent an increase in the work load for remaining nurses, thus precluding a dose-response effect.

It is interesting to note that psychiatry was the care unit mostly affected by sick leave in group A. One study has reported that nurses from a psychiatry unit declared more health problems than nurses from any other care unit, but the authors did not give the precise health problems reported. ${ }^{11}$ The fact that health care units showed hardly any association with absence would support Dewe's idea that certain constraints are inherent to nursing and others are particular to each care unit, but that no one unit is completely exempt from constraints. ${ }^{12}$

Even though all the establishments were subjected to the same collective bargaining and the same collective insurance, certain hospitals with the highest numbers of leaves were characterised by a closely involved health service and the production of statistics for sick leaves, which could indicate a stricter follow up of short leaves. This would support the hypothesis that a policy to control short leaves more rigorously, thus preventing nurses from taking one or two days off to recuperate even though not clinically ill, would favour an increase in long leaves. Also, the work overload brought about by nonsystematic replacement of short leaves could account for a part of the different level of leaves within hospitals mentioned by Bernier et al, ${ }^{13}$ Bureau and Genin, ${ }^{14}$ and Leppanen and Olkinuora. ${ }^{15}$ Another explanation could be that certain types of diagnoses 
are viewed differently in different hospitals-for example, psychosomatic diagnoses. This has been supported in one hospital where symptoms attributed to a bad ventilation system have contributed to the hardening of both union and employer's positions about psychosomatic problems. The lack of acknowledgement of a medical problem by the employer for a number of years and the fact that compensation for that problem is impossible lead some nurses to ask their physician to put a diagnosis more acceptable to the employer and the insurance company, thus contributing to a reduction in the number of diagnoses fitting into group $A$ in that hospital.

Full time permanent nurses were absent more often than nurses with another job classification. This finding could be foreseen not only because full time permanent nurses had less time to recuperate physically and psychologically but also because they had better conditions for admissibility to idemnity than both temporary and part time nurses. The duration of the absences was much longer, however, among the part time nurses $(p=0.012)$, thus supporting the hypothesis that health problems become more serious when the period of recuperation is postponed.

Also, the fact that job classification correlated with the other time variables in the study-namely, age, seniority in the hospital and in the current position, and in a certain measure to the title-could confound the association between these variables and sick leave.

Work schedule did not influence sick leave for all diagnoses but night and evening schedules had an effect on absence due to group A diagnoses. This suggests that evening or night work affects the mental wellbeing of workers. Similar results were found by other researchers on the effect of work schedules on health. ${ }^{16-19}$

\section{STRENGTHS AND LIMITATIONS OF THE STUDY}

Some strengths and limitations have already been mentioned in a previous article. These are data quality, the precision of the exposure variables concerning workload, and the lack of information regarding extraprofessional life as potential confounding factors. ${ }^{3}$ We shall only summarise these issues and put the emphasis on validity questions.

\section{OBJECTIVE MEASURES CHARACTERISING THE} DEPENDENT VARIABLE AND THE WORK LOAD

The use of sick leave as a morbidity indicator offers the opportunity to use data banks routinely collected by employers for administrative purposes. It allows a non-subjective measure of morbidity that can be assessed in relation to characteristics of work organisation. Exposure may have been misclassified, however, because of the lack of precision in the exposure variables.

Confounding in the data may have occurred because of lack of information on extraprofessional life factors that may be related to sick leave; especially marital state, number of children, smoking, alcohol consumption, and medication. These factors have been associated with short leaves but their association with longer certified sick leaves has not yet been shown.

\section{VALIDITY ISSUES}

Sensitivity concerns the capacity of an indicator to designate sick people as sick when they are. When compensation clauses exist there are strong chances that a sick person will take leave from his work.

Specificity concerns the indicator's capacity to include among people who do not take sick leaves only people who are not sick. Those people who may go to work when they are sick are hardly identifiable. It is easier to evaluate specificity by estimating how many persons benefit from a sick leave without being sick. In each hospital, this estimation is possible by the examination of the policies or control mechanisms concerning absence, that is, medical certificate and administrative verification of leaves, particularly compensated ones. In the seven hospitals of the study, the control mechanisms are rather standardised for long leaves and a more or less rigorous control of short leaves could explain the differences in incidence of sick leave between hospitals.

For the diagnoses the physicians classified the reasons for sick leave into three, the leaves most likely to be related to work load, the leaves possibly associated, and the leaves not associated with work load. Bias could occur if a diagnosis was included in the wrong category, and this could produce an over or underestimation of the OR. We adopted a conservative approach in keeping only the first group of diagnoses in the analysis, the ones for which the physicians had the greatest certainty of their likely association with work load.

Another major problem concerns group A diagnoses. This group contains mostly mental health problems, which are more likely to be underreported because they have a pejorative connotation and are harder to declare. This group also includes certain health problems, such as burnout, which the insurance company refuses to recognise and compensate. It is the opinion of nurses' union representatives, however, that nurses ask their physicians to put on the medical certificate a compensable diagnosis. We could not verify if in those particular circumstances, certain diagnoses were declared more often than others by the physicians or if those diagnoses were more or less related to the initial one, in which case the inclusion in the group A diagnoses would not have entailed misclassification. 


\section{Conclusion}

The evaluation of objective constraints in the work organisation needs to be pursued. In fact, the exposure variables examined in this research on nurses are promising and a more precise measure of nurse-patient ratio and duration of stay for each care unit would allow a better estimation of their association with sick leave.

Our study supports the relevance of using certified sick leave as a non-specific indicator of morbidity. This indicator is mostly useful for research on the effect of work organisation on health because of its ability to consider health outcomes on several organs or systems.

In our data, this indicator proved better when restricted to a group of diagnoses "most likely to be related to work load." There is still work to be done to specify the groupings of diagnoses that would be the most pertinent to examine in relation to particular organisational constraints in work.

This research was funded by the Conseil québécois de la recherche sociale. We thank the management of the hospitals, la Fédération des infirmières et infirmiers du Québec, for their cooperation; Dr F Meyer for his advice regarding analysis; and Dr R Plante, and Dr P Auger for the coding of diagnoses.

Requests for reprints to: Professor Renée Bourbonnais, Groupe Interdisciplinaire de Recherche sur l'Organisation, la Santé et la Sécurité du Travail (GIROSST), Département de Médecine sociale et préventive Pavillon de l'Est Université Laval, Québec, Province de Québec, Canada, G1K 7P4.

1 Coté-Desbiolles LH, Morissette R. L'absence du travail. Québec: Publication du Ministère du Travail du Québec, 1985.

2 Bourbonnais $\mathbf{R}$, Vinet A. L'absence du travail comme indicateur de santé: signification, mesures et conditions d'utilisation.
Revue d'épidémiologie et de santé publique 1989;37:173-82.

3 Bourbonnais R, Vinet A, Meyer F, Goldberg M. Certified sick leave and workload. A case-referent study among nurses. J Occup Med 1992;34:69-74.

4 Bourbonnais R, Lee-Gosselin H, Pérusse M. L'organisation du travail en milieu hospitalier et ses effets sur la santé des infirmières. Santé mentale au Québec 1985;X:73-85.

5 World Health Organisation. Manual of the international classification of diseases, injuries, and causes of death. Eighth version. Geneva: WHO, 1978.

6 Fleiss JL. Statistical methods for rates and proportions. Toronto, Ontario: John Wiley, 1981.

7 Kleinbaum DG, Kupper LL, Morgenstern H. Epidemiologic research: principles and quantitative methods. Belmont, CA: Lifetime Learning Publications, 1982.

8 Kleinbaum DG, Kupper LI. Applied regression analysis and other multivariate methods. Boston, MA: Duxbury Press, 1978.

9 Breslow NE, Day NE. Statistical methods in cancer research. Vol 1. The analysis of case-control studies. Lyon: International Agency for Research on Cancer, 1980. (IARC sci publ No 32.)

10 SAS Institute Inc. $S A S$ user's guide: statistics. Version 5, Cary, NC: SAS Institute, 1985.

11 Boulard R. Caractéristiques de l'organisation du travail et santé mentale des infirmières: un premier diagnostic. Rapport de recherche, Département de médecine sociale et préventive. Québec: Université Laval, 1988.

12 Dewe PJ. Investigating the frequency of nursing stressors: a comparison across wards. Soc Sci Med 1988;26:375-80.

13 Bernier J, Bellemare G, Brabant L. L'impact des conventions collectives sur l'allocation des ressources humaines dans les centres hospitaliers. Rapport de recherche, Relations Industrielles. Québec: Université Laval, 1987.

14 Bureau N, Genin MG. Absentéisme du personnel soignant: approche socio-économique. Gestions Hospitalières 1981; 205:343-60.

15 Leppanen RA, Olkinuora MA. Psychological stress experienced by health personnel. Scand $J$ Work Environ Health 1987;13: $1-8$.

16 Estryn-Bèhar M, Kaminski M, Peigne E, et al. Stress at work and mental health status among female hospital workers. $\mathrm{Br} J$ Ind Med 1990;47:20-8.

17 Estryn-Béhar M, Gadbois C, Vaichère E. Effets du travail de nuit en équipes fixes sur une population féminine. Résultats d'une enquête dans le secteur hospitalier. Arch Mal Prof 1978;39:531-55.

18 Logeay P, Lert F, Chastang JF, Monod H. Le temps des infirmières des contre-temps à la santè. Enquête épidèmiologique sur les infirmières des hôpitaux publics. Paris: CNRS-INSERM, 1986.

19 Pérusse M, Drabkin P, Pelletier M, et al. Les effets du travail en milieu hospitalier psychiatrique sur la santé des travailleurs. Rapport de recherche, Département de médecine sociale et préventive. Québec: Université Laval, 1984.

Accepted 27 January 1992 